\title{
Benefits and Difficulties of Learning in Group Work in EFL Classes in Saudi Arabia
}

\author{
Nurah Alfares ${ }^{1}$ \\ ${ }^{1}$ Department of Curriculum and Instruction, College of Education, Umm AL-Qura University, Makkah \\ Al-Mukarama, Saudi Arabia \\ Correspondence: Nurah Alfares, Department of Curriculum and Instruction, College of Education, Umm \\ AL-Qura University, Makkah Al-Mukarama, Saudi Arabia. E-mail: nsfares@uqu.edu.sa
}

$\begin{aligned} & \text { Received: April 20, } 2017 \quad \text { Accepted: June 15, } 2017 \quad \text { Online Published: June 19, } 2017 \\ & \text { doi: 10.5539/elt.v10n7p247 } \quad \text { URL: http://doi.org/10.5539/elt.v10n7p247 }\end{aligned}$

\begin{abstract}
This study investigates learners' perceptions of the benefits and the difficulties of group work (GW) in EFL (English as a foreign language) classes. The purpose of this study is to explore the possible effects of GW, in order to better understand learners' attitudes towards GW, and to inform language teachers of students' views of using GW. A mixed-methods approach (quantitative and qualitative methods) was used to collect the required data for the study. Questionnaires were collected from 188 students in five private language institutions. These institutions specialise in teaching EFL to adult students studying in intermediate and secondary schools. From this sample, 20 students were interviewed in more detail in follow-up telephone interviews. The questionnaire examined learners' general perceptions, and the telephone interviews further explored the questionnaire findings. The findings revealed that many language learners consider the advantages of GW to be mainly related to (1) cognitive aspects, i.e. benefits that help learners in the learning process; and (2) emotional aspects, which are benefits that enhance motivation for learners. However, some learners identified difficulties, mostly related to learners' behaviours, which can result in uncooperative work in groups. These findings revealed that Saudi learners regard GW as effective in learning, but that some students' negative behaviours may prevent them from obtaining the benefits of GW.
\end{abstract}

Keywords: cooperative learning, communication, EFL, group work, interaction

\section{Introduction}

In this article, Saudi learners' perceptions of the benefits and difficulties of GW in EFL classes are explored. The perceived benefits of GW that help learners in learning EFL are presented, as well as the difficulties that some learners face when working with other learners in GW. An important issue is that although GW may help EFL learners to improve their language skills, sometimes working with other learners could be detrimental to some group members. Thus, it is hoped that this study will provide useful evidence that will enable teachers to aid learners in realising the potential benefits of GW. Moreover, it will increase teachers' understanding of the reasons for the difficulties in GW, which may relate to the dynamics of GW or to learners themselves. Furthermore, exploring the benefits and difficulties of learning in GW could provide opportunities for interested researchers to conduct related studies that will examine GW's benefits and investigate the explored difficulties.

\section{Theories of Communication and Interaction in Language Class}

In language teaching, the communicative method was established based on a theory of language as communication (Richards \& Rodgers, 2001). Communication among language learners may facilitate language acquisition: for instance, language learners often start to interact in a second language (L2) as they did as children when they were learning their first language. According to Krashen (1982), language acquisition is the process of subconscious learning, in which language learners can acquire a language naturally.

Interaction theories have indicated that L2 acquisition could be improved by giving learners the opportunity to negotiate meaning (Long, 1983; Richards, 2005). Previous researchers emphasised the importance of negotiation of meaning, as this helps to increase the comprehensible input of learners (Oliver, 1998; Pica, 1996; Schinke-Liano \& Vicars, 1993). Meaning can be negotiated through methods such as the following: the speaker checks others' understanding, the listener asks for more explanation, and the listener asks for repetition. 
Language learning can be improved when learners repeat the language elements they hear, such as the subject-verb agreement rules (Lightbown \& Spada, 1999). By listening to other students' use of rules, students may achieve accurate utterances in the target language.

The basic goal of communicative language teaching is the achievement of communicative competence. Krashen (1982) proposed the input approach to language acquisition: this approach rejects the role of explicit instruction in teaching. He claimed that learners can acquire the language naturally; furthermore, they can acquire vocabulary and grammar if they receive input, and can improve their speaking ability if they have a sufficient quantity of comprehensible input. Therefore, Krashen indicated that grammar instruction is of lesser importance in language teaching. Some researchers (Gass, 1997; Long, 1996; Pica, 1994) have found that when learners engage in negotiation activities, their awareness may be focused on both the form and meaning of language. Therefore, interaction could help learners to be aware of their comprehension abilities. Interaction is an important aspect of the language-learning process, as it gives learners the opportunity to negotiate meaning; this leads to positive developmental effects and an increase in a comprehensible input, pushed output (Richards, 2005; Swain, 1995; Ellis, 1994).

Hall and Hewings (2001) suggested that learning a language is a process which develops through interaction between learners, teachers, texts and activities. However, Ellis (1994) concluded from previous studies that learner-learner interaction is more effective than teacher-learner interaction in helping learners to acquire L2. Furthermore, Richards (2005) claimed that groups help learners to perform more negotiation, as the more relaxed environment helps them to negotiate with others without pressure.

\section{Benefits of Group Work in Language Learning}

An important aim of group work (GW) is to encourage fluency in language. In language classes, GW is a strategy that enables students to discuss issues or to engage in joint activities with other students in a less threatening environment (Harmer, 1991). Particularly in EFL classrooms, grouping is said to be an effective method of teaching for several reasons; for instance, it maximises the time that students can speak the target language. In addition, it minimises the time that students spend listening to other students interacting with the teacher; furthermore, it avoids the anxiety that hinders some language learners from speaking and interacting with the teacher in front of the whole class; and it gives the teacher more opportunities to discuss with students the structure of the task (Foster, 1998).

Groups may allow students to be more independent, because they are encouraged to teach others and also to learn from others. In contrast, in teacher-fronted situations, students may be more dependent because the teacher is doing most of the talking. Several researchers (Brown, 2001; Foster, 1998; Ghaith \& Yaghi, 1998; Harmer, 1991) have claimed that GW is efficient in language classrooms because it gives learners the opportunity to practise English with their group members. Furthermore, group work maximises the benefits for students in the classroom. Specifically, it can be used to improve oral activities for language learners, to complete tasks that need discussion among learners, to share reading and listening activities, and to write cooperatively with other learners. It also has the great advantage of allowing different groups of students to perform different tasks and activities according to their ability (Harmer, 1991).

McDonough (2004) explored instructors' and learners' perceptions of the use of pair and small-group activities in a Thai EFL context, and examined whether the learning opportunities theoretically attributed to these activities occurred in an intact classroom. He also investigated whether learners who actively participated during the pair and small-group activities showed improved production of the target forms. The results indicated that learners who engaged in more participation during the pair and small-group activities demonstrated improved production of the target forms, although they did not perceive the activities as useful for their learning.

\section{The Dynamic of Group Work in the Language Class}

The study of group dynamics relates to the scientific analysis of group behaviour: it concerns both group life and group characteristics. Clement, Dörnyei and Noels (1994) claimed that group dynamics has been a core area of social psychology for several years: it concerns the scientific analysis of the dynamics of small-group behaviour, and focuses on issues such as group formation and development, group structure and group processes.

Cohesiveness, seating arrangements, group size and group composition could affect the process of group dynamics (Storch \& Aldosari, 2010; McCafferty, Jacobs \& DaSilva Iddings, 2006). Students in a cohesive group have a strong connection with each other, as they talk more and share their ideas together (Dörnyei \& Murphey, 2003). Senior (1997) conducted a study to explore the perceptions of experienced English-language teachers on the nature of 'good' English language classes. The findings show that teachers judged the quality of their classes 
according to how well the students cooperated with each other to form single, unified classroom groups. They clearly perceived that any class with a positive whole-group atmosphere was 'good', whereas any class which lacked a spirit of group cohesion was 'unsatisfactory', even if it was composed of high-achieving students.

Dörnyei and Murphey (2003) claimed that after the teacher has assigned students to groups, the different characteristics and behaviours of students start to emerge. For example, in some groups there will be students who want to lead, and others who want to follow. Some students take more than one role and change it from time to time, while others take one role unconsciously and usually maintain it. Student leaders emerge in almost all groups, and they tend to control and supervise GW.

Assigning a single role to each member of the group may be more effective in achieving successful GW (McCafferty et al., 2006; Dörnyei \& Murphey 2003). Some researchers (McCafferty et al., 2006; Cohen 1994) also claimed that the group would be efficient if every member has something specific to do, such as asking for and giving information, giving examples, synthesising and summarising, and taking notes and recording information. Dörnyei and Murphey (2003) suggested that specifying roles for each member may improve the learning, as well as promote the development of different abilities; moreover, it may decrease the anxiety of group members, as they know what they are expected to do.

According to motivational theories, students will be motivated to help their group when the group members are cooperative (Pan \& Wu, 2013; Slavin, 1983). The cohesiveness of the group mediates the learning; furthermore, students may be motivated to help their fellow students because they have to care about each other to achieve successful learning through group cohesion (Prichard et al., 2006). Thus, it is evident that motivation influences achievement directly: it plays an important role in L2 learning (Oxford \& Shearin, 1994).

\section{The Study}

\subsection{Purpose}

Previous researchers (e.g. Al-Seghayer, 2011; Zaid, 1993) have claimed that, in public schools, Saudi students study English with an emphasis on learning the content of the language, rather than using English in communication situations. This is because reading and writing may be seen as more important than oral communication. Further, many researchers (e.g. Al-Maiman, 2005; Al-Motairi, 2005; Zaid, 1993) have stated that parents, teachers and pupils agree that the teaching and learning of English in schools is unsatisfactory, leading to weak performance of students in English. The large number of students in the classroom could lead to ineffective learning of EFL. Also, the arrangement of the classroom in Saudi schools is not appropriate for the implementation of grouping.

Al-Seghayer (2011) mentioned that there is a mismatch between some of the goals and objectives of teaching English in Saudi public schools and the methods used and promoted by the Ministry. The common methods of teaching English in Saudi public schools are the Audio-Lingual Method, the direct method, cognitive code learning and grammar translation. These teaching methods seem to focus more on the content than on the usage of language, and are thus less likely to help students to communicate fluently in English. In addition, the promotion of these methods through the curriculum further demonstrates that Saudi teachers are not advised to teach communicative competences, or to encourage students to speak English in class. Moreover, they stated that many parents are unhappy with the English lessons their children receive: this might explain why they send children to private schools, where English lessons taught effectively and achieve the required results.

In Saudi Arabia, current research in EFL is very limited: most of the research focuses on materials and teacher preparation rather than on methods of teaching. The review of evidence shows that teachers do not generally use communicative methods in public schools, which may affect students' learning of English, in that they can 'receive' the new knowledge, but they cannot produce it. Sheikh (1993) suggested that group work (GW) could be a possible solution to maximise class time and allow learners to participate in the EFL classroom in Saudi Arabia; she stated that learners can apply their understanding of the language when learning in groups, and also proposed GW as a solution for the large EFL classes in Saudi Arabia.

Some recent research on communicative and cooperative teaching methods has been conducted in Saudi Arabia. For instance, Al-Twairish (2009) assessed the effect of implementing the communicative approach on Saudi secondary students' listening and speaking skills in EFL. The result indicated that a communicative approach had a positive result on the students' listening and speaking skills, to such an extent that the researcher recommended changing the curriculum from non-communicative to communicative, and also, that EFL teachers should be trained to implement communicative methods. Al Mugren (2009) conducted an experimental study that compared the effects of the Cooperative Language Learning Approach (CLL) with the traditional method of 
improving the writing ability of students in the English department. The results showed that CLL had a positive effect on improving students' composition writing, and was more effective than the traditional methods of teaching EFL learners. These experimental studies demonstrate the effective results of communicative and cooperative learning in the EFL classroom.

The present study aims to explore learners' perceptions of the benefits GW provides to success in learning. Furthermore, it aims to investigate learners' attitudes towards GW, by discovering the barriers that GW may pose in learning. Because few studies have been conducted to investigate the learners' perceptions, attitudes and impressions of GW in EFL, it seems appropriate to conduct an exploratory study which provides clear knowledge of learners' perceptions of GW in the EFL classroom.

Due to the reasons mentioned above, the proposed study will focus on provisions in private institutions. In the private sector, as mentioned in most EFL institution websites, communicative methods are used to help students practise English in the language classroom. Many of these institutions state that giving students the ability to use English in social life is one of their aims. In addition, they aim to have smaller class sizes than public-sector schools, with no more than 15 students in each class. Lessons may last up to two hours in some institutions, and they use up-to-date materials. In contrast to the situation in public schools (Sheikh, 1993), most private institutions claim to use student-centred methods rather than teacher-centred ones.

Two questions have been set to achieve the purposes of the study:

1. (A) What are the explicit benefits that Saudi EFL learners identify in relation to group work?

(B) If there are any benefits, what are the perceived impacts of these benefits on students' learning?

2. (A) What are the difficulties of group work that Saudi EFL learners identify in the learning context?

(B) If there are any barriers, how are these perceived by Saudi EFL learners?

\subsection{Data Collection}

Two methods have been used to investigate the two research questions. A questionnaire was used to explore the first part of each question (A), while interviews with students were conducted to explore the second part (B) of each question. The last question in the questionnaire was asked to obtain the participants' details, in order to elicit a sample for the follow-up interviews. Ten EFL institutions were chosen to participate in this study, based on these criteria:

1) The institution had to make use of GW in their English language teaching (ELT) classes.

2) The head of the institution had to agree for the school to take part in the study.

3) Institutions had to be from different regions of Saudi Arabia, given that the researcher wanted to collect data from different areas in order to ensure a geographical spread of the participants.

The researcher contacted ten language institutions, mainly identified through internet searches. Four of them were in the capital city of Riyadh, three institutions were in Jeddah, and the other three were in Makah. These three cities are different in size, environment, culture, population and geography. The researcher believes it is possible that the culture and the development of the education system and local educational policies in each city may reflect people's behaviours and attitudes. For example, the capital city has greater number of highly developed educational centres than small cities; these centres are more likely to follow the recent developments in teaching EFL. Riyadh, as the capital city, is one of the most developed cities in Saudi Arabia, and is located in the centre of the country. Jeddah is also regarded as one of Saudi Arabia's most highly developed cities, as it is a main centre of trade and business. However, it possibly has a different culture from Riyadh, as it is located in the west of Saudi Arabia; therefore, there may be differences between the cities in terms of culture and how language institutions promote EFL. Finally, Makah is a small city, so it is possible that it has a different culture from Riyadh and Jeddah. The researcher did not aim to compare language institutions in these three cities, but aimed to collect data from different areas in order to obtain different perspectives of EFL learners, on the basis that various social factors could affect learners' opinions.

After the first contact was established on the phone, six of the ten institutions contacted agreed to participate in the research, and four refused to take part. Three of them refused because their internal policy did not allow external research to take place in the school; the fourth one did not give a reason. Three of the six institutions were in Riyadh, two were in Makkak, and one was in Jeddah.

The researcher then visited the consenting institutions, and a consent form was signed by the head teacher. The questionnaires were distributed only after the head teacher of the institution had provided the signed consent 
form to the researcher. Only the first institution allowed the researcher to distribute the questionnaire directly to the students, and to meet the students and discuss the study before handing them the questionnaires. The others asked the researcher to leave copies of the questionnaire and offered to distribute them to the students at a convenient time. The researcher distributed 400 questionnaires to students in the six EFL centres, and 198 were returned. The sixth EFL centre was excluded because it did not fulfil to the required criteria; thus, ten questionnaires were excluded from analysis.

In total, 87 students volunteered to be interviewed. The participants in the telephone interviews were selected on the basis of their answers to the questionnaires, as highlighted in the list of criteria below. The group selected included a mix of male and female students, spread across the four institutions. The criteria for selecting students to participate in the telephone interviews were:

1) Students to be from different institutions: a selection from the four institutions.

2) Students were willing to participate in the telephone interview.

3) Students had provided noteworthy or ambiguous answers in the questionnaire, and the researcher wanted to ask for clarification. The selection was made randomly among those participants who fulfilled this criterion, and they were elicited without biasing to some answers.

4) Students could be contacted by phone.

\section{Results}

The researcher asked the participants in the questionnaire an open-ended question in order to collect students' views on the benefits and difficulties of GW. Also, students were asked to rate a list of benefits and difficulties of GW. These questions helped the researcher to decide the focus area in the follow-up interviews. By identifying the main benefits and difficulties of GW through the students' answers in the questionnaire, mainly the open-ended questions, the researcher investigated the learners' answers in greater detail in the follow-up interviews. The results of the open-ended questions and the telephone interviews were combined in order to present the significant results of the study.

\subsection{Findings of the Perceived Benefits of Group Work}

\subsubsection{Perceived Cognitive Benefits of Group Work}

The majority of the learners explained that they were happy to work in a group because doing so enabled them to get help from their peers. Learners explained that it was not easy to ask the teacher to clarify ambiguities or questions they had. Thus, it appeared that, perhaps due to a rather formal relationship between language learners and their teachers, language learners seemed to prefer to ask other group members to clarify specific issues for them. Further, learners explained that they understood an explanation better when their group members answered their questions.

In addition, students felt that, in a group, people have different experiences and knowledge to share with others. For instance, Razan explained that getting help from others in the group may result in greater learning progress. She suggested that GW provides an opportunity for assistance between group members, as students who ask for help from other group members would then help others who needed their assistance:

I prefer group work because if I need an explanation or a clarification, the other group members will help me, and if they need an explanation, I wouldn't hesitate to explain things for them. I prefer group work than learning by myself ... Group work is useful for me because if I don't know a word in English, I can ask my friends and I may also know the meaning of some words that they need. (Razan, female, 15, Institution C)

It is clear that swapping information and knowledge between students can increase the cooperative learning opportunities in GW. Teaching and helping other students can, in turn, improve the learners' own understanding of the language. Furthermore, Mazen believed that language learners pay more attention to peers' explanations than to those of the teacher: this is because the teacher has to teach the whole class, rather than focusing on supporting specific individuals. He believed that the close relationship between learners helped them stay focused in the group. In his view, the positive relationship between group members can lead to greater concentration in GW. He explained:

I think group work is better than individual learning ... You know that if the teacher explains to the whole class, some students may not pay attention to the teacher's explanation, but if we study within a group, the situation is different; the students will focus on what others say since they are closer to each other. (Mazen, male, 19, Institution D) 
Another important point is that learners felt more at ease in practising and speaking English with other students than with the teacher. Lola explained that the difficulties of speaking with the teacher would disappear in GW:

In groups, we can discuss things together and not speak with the teacher. I feel nervous when I speak to the teacher because of course she knows more than me, but when I speak to other students, all these barriers disappear. (Lola, female, 19, Institution D)

Lola felt confident about speaking with other learners because her level of English was closer to theirs than to the teacher's. Other students claimed that speaking with other learners could help reduce the power barriers that normally exist in a teacher-learner interaction. Therefore, it appears that communication with the teacher is more stressful than engaging with peers in GW.

Interestingly, some learners thought that speaking in a group has helped them speak English more confidently outside class, too. The GW in a language class offers a supportive environment for learners to prepare themselves to speak in a larger social environment. Extracts from Jeyan's interview clarify this point further:

Of course group work helped me a lot ... For example, I could not speak English outside the classroom before, but I practise speaking with my friends in the group in class, which will help me and encourage me to speak, so if I go outside the classroom I can speak confidently. (Jeyan, female, 15, Institution C)

These learners implied that practising speaking with their groups members helped them improve their communicative skills, which became useful in their social life. It appears that motivation and confidence in speaking English may improve when it starts in a smaller environment and it is then applied in a wider social context.

\subsubsection{The Perceived Emotional Benefits of GW for Language Learners}

Learners explained that the competition between group members, in which all of them worked hard to stand out, had a positive effect on motivating students to exchange ideas and knowledge. Thus, positive competition in GW may result in motivating students to support each other. Also, GW could create a positive environment which helps learners improve their language skills. One student, Lola, mentioned that learning in GW made the learning atmosphere more interesting than learning alone. She said that GW gave her an opportunity to exchange knowledge and share experiences with others, which made her actively involved and enthusiastic to learn:

To be honest, nobody can learn in a boring atmosphere like in a school or learn by themselves, especially when learning a second language. At the college, it was more fun, and the best thing in $G W$ is the opportunity to exchange experiences ... When a student studies alone, they will get bored, but when they are studying with other students, the atmosphere will be better for learning. (Lola, female, 19, Institution D)

Additionally, some learners explained that working with others in a group makes them enthusiastic to learn from their peers, as well as to teach those who need help. They explained that GW gives the students more motivation to learn than individual learning, especially in the case of low-ability students, since they may need more support from other learners. Also, for some students, the motivation generated by being in a group could increase the opportunities for cooperative learning between group members. On this subject, Meyada explained:

My group was very cooperative and this was helpful for me. All the group members were enthusiastic about learning and if anyone didn't understand something, the other members tried to help and explain. (Meyada, female, 24, Institution D)

Language learners also suggested that being motivated could help them progress in learning English, because group members seemed to work cooperatively to support each other. In summary, this section has presented the perceived emotional benefits of GW. However, some learners suggested that GW is not always a positive activity, and sometimes impacts negatively on language learners: this aspect will be explored in the following section.

\subsection{Findings of Perceived Difficulties of $G W$}

\subsubsection{Perceived Learning Difficulties in GW}

Learners explained that they sometimes regarded learning in groups as 'a waste of time'. This was especially the case in mixed-ability groups, in which students with different levels of ability are asked to work together. Some learners mentioned that in these groups, certain students tend to ask their peers for help too many times. They thought this might irritate other group members, since an excessive number of questions could interrupt their concentration. This is an example from the students' interviews:

When you learn by yourself, there is no time-wasting like in group work, where one of the group members may ask many questions or they need more explanation because their level of English is not so good, all this will 
waste lots of time when you work in a group. (Mohannad, male, 29, Institution C)

Mohannad explained that different abilities in group work may result in time-wasting, as some students need more time to understand things properly. Mohannad believed that this disadvantage does not exist when you learn individually. Furthermore, some learners found it very difficult to convey their ideas and knowledge to others when working in groups. Language learners differ in their knowledge, experience, abilities, and characteristics, even when they have the same level of language competence. These differences may cause barriers for some learners in working cooperatively in groups. Hisham explained:

If I work with lower-ability students, it is usually difficult for me to discuss something with them or have a conversation, because they would not understand me. (Hisham, male, 22, Institution C)

Another important point is that some students would sometimes ask others for clarification in Arabic if they had difficulties in understanding the explanation in English. It seems that while it is easier for some learners to clarify their understanding in their native language, this may annoy more advanced learners, as they see this as taking time from their learning progress in English. Waseem believed that usage of the native language should not be allowed while learning a second language. He explained:

When some students in the group do not understand some vocabulary, they translate it into Arabic or they ask other students the meaning in Arabic, and I think this is wrong when you want to learn English. (Waseem, male, 25, Institution A)

\subsubsection{Perceived Emotional Difficulties in GW}

Communication in GW is very important if learning is to take place. Meyada believed that working with a lively group may encourage her to participate and contribute more than when being part of a quieter group. Furthermore, Meshary mentioned that shyness may be a barrier for individuals when they need to ask others for help, and this may negatively affect cooperative learning. He explained:

I think a big difficulty is some people's shyness. If the student is shy, they won't ask other group members if he or she needed any help, and this will affect negatively their learning. (Meshary, male, 20, Institution A)

Another important point is that some students complained that people in groups may have a very negative influence on individuals, through behaviours such as ignoring colleagues who need help in the group. In relation to this, Lola said:

I remember that I missed a lesson, and when I was back at school, I was working with a group of three students, and they totally ignored me because I did not have any idea about the previous lesson, so I kept silent all the time. This was a negative experience for me of working in a group. (Lola, female, 19, Institution D)

Lola described being ignored in GW as one of the negative behaviours which may prevent students from benefitting fully in GW; she believed that being ignored could prevent some group members from getting the support that would help them learn. The findings indicated that anxious students and shy learners could be affected negatively by being asked to interact in a group, and this might also impact negatively on their group peers. Also, ignoring some members of the group may lead to uncooperative GW.

\section{Discussion of the Findings}

Although some learners perceived some difficulties of learning in GW, several students saw that GW provided clear benefits for learning a foreign language. Learners explained that more interaction in GW could help them become aware of their mistakes, due to receiving feedback from others. Thus, GW helps students develop their accuracy in the target language. This result appears to support previous research (Gass, 1997; Long, 1996; Pica, 1994) on the role of the interaction hypothesis in L2 acquisition. Specifically, this finding suggests that interaction in the classroom may help language learners to gain the appropriate feedback that will enable them to identify grammatical errors, thus leading them to produce accurate utterances in the target language.

It appeared that learners experienced difficulties in contacting the teacher to clarify some points in the lesson. Previous research (Damon, 1984; Bejarano, 1987) showed the following advantages of group interaction: students can speak at a level that other students can understand; students can confront each other and try to resolve any disagreements; students can gain feedback from other students; and they can more easily accept corrections from other students. The familiarity of learners with other group members' misunderstandings of specific aspects of the target language often results in swapping assistance when learning in groups: for instance, students help other learners with specific language issues, as well as receiving help with issues that they are not familiar with. Consequently, both parties could benefit from the process, as helpers may improve in the target language through providing teaching and explanation to other members (Lier, 1996; Allwright, 1984; Imai, 
2010); moreover, people who need help will receive the required assistance and solve their learning problems (Brown \& Palinscar, 1989). This indicates that giving and receiving explanations works as an essential component of scaffolding in GW (Webba \& Mastergeorgeb, 2003).

Furthermore, GW appears to make the learning environment more enjoyable for language learners. A pleasant environment in the EFL classroom may impact positively on academic achievement. This result is consistent with a previous study by Martinez et al. (2002), which investigated students' perceptions of GW: their results indicated a positive relationship between the degree of preference for GW, enjoyment of GW activities and academic results.

Although this study was conducted in Saudi Arabia, which is a different context from those of previous studies, the results indicating the benefits of GW seem to be in agreement with some of these former studies. For instance, Garrett and Shortall (2002) found that GW could achieve the following: increase the shared help between students; allow them to practise the language more; increase concentration in learners and their engagement with the interaction sitting; and reduce anxiety in language learners. According to a study by McDonough (2004), which investigated learner-learner interaction through pair and group work in a Thai EFL context, several students said that talking to others was helpful for them in learning English. The reasons they gave were varied: some indicated that talking to others would help them because their friends could explain what the teacher said; others indicated that it was good to practise oral English; yet another group said that GW was useful for learning vocabulary and grammar.

However, learners explained that some learning-related and emotional barriers were encountered in GW. Language learners expressed negative views of GW if they felt that learning was not achieved; they perceived that GW was a waste of time if they worked with others without gaining any benefits for their own learning. These findings could be the result of working with mixed-ability groupings, where the low-ability students might ask many questions to clarify their understanding.

Another potential disadvantage of GW is that a certain level of anxiety in GW may result in a lack of cooperation between group members. It appears from the data that some language learners do not like to work in groups where certain individuals feel shy and do not participate. A possible reason is that students of low proficiency in the target language may feel less confident about contributing to the group. Also, if these shy learners were working in a relatively large group, the group size may be a barrier to their communication with others.

The major findings of the current study can be summarised in two points. First, language learners identified many benefits of learning in GW, mostly related to advantages for EFL learning. It has been found that, in learners' opinions, GW seems to be beneficial for their academic learning, motivation to learn, and the development of knowledge. Learners perceived that GW creates a more friendly, supportive learning environment, within which students have more opportunities and more freedom to practise English. Learners have seen that GW creates natural, real-life interactions, in which they have logical reasons for listening to one another, asking questions, clarifying issues and helping each other. These interactions seem to increase the amount of student talk and student participation in the classroom. The second major finding refers to the negative effects and difficulties that language learners perceived in GW. These related mostly to learning and emotional aspects: these must be taken into account by language teachers when planning to use GW, as the learners' attitudes towards GW are affected by these perceived difficulties. Specifically, the main difficulties identified by learners in this study related to the selection of groups and the criteria used for this selection. Thus, if members are not appropriately selected, GW may result in missed learning opportunities in EFL for language learners. There appears to be a diversity of students' opinions with regard to group composition: taking these preferences into account when classifying them into groups may reduce the potential difficulties that may impact on learning. Another important issue is that the negative attributes of some language learners may affect GW negatively.

Finally, the implication for teachers is that they should make efforts to identify the aspects that can assist the promotion of cooperative learning in $\mathrm{GW}$, in order to reduce the negative behaviours of some group members, as well as to promote motivation in learning. The findings could also be useful for students, in enabling them to understand how learning in groups can positively affect their learning of the English language.

\section{References}

Al-Twairish, B. N. (2009). Effect of the communicative approach on the listening and speaking skills of Saudi secondary school students: an experimental study (Unpublished master's thesis). King Saud University, Riyadh, Saudi Arabia. 
Allwright, R., (1984). The importance of interaction in classroom language learning. Applied Linguistics, 5, 156-71. https://doi.org/10.1093/applin/5.2.156

Al-Maiman, I. (2005). A Study of Seventh-Grade Saudi Students' Motivation Level to Learn English as a Foreign Language (Unpublished doctoral thesis). University of Kansas, State of Kansas, U.S.

Al-Motairi, A. (2005). Towards Improving the Teaching of English as a Foreign Language in the Saudi Context: A Case Study in Five Saudi Boys Secondary Schools (Unpublished doctoral thesis). University of East Anglia, Norwich, England.

Al Mugren, M. (2009) The Impact of Cooperative Language Learning on Improving the Writing Competency of Third-Year English Majored College Students (Unpublished master's thesis). Al Imam Muhammad Ibn Saud Islamic University, Riyadh, Saudi Arabia.

Al-Seghayer, K. (2011). English teaching in Saudi Arabia: Status, issues, and challenges. Riyadh, Saudi Arabia: Hala Printed Co.

Bejarano, Y. (1987). A Cooperative Small-Group Methodology in the Language Classroom. TESOL Quarterly, 21(3), 483-504. https://doi.org/10.2307/3586499

Brown, A. L., \& Palinscar, A. S. (1989). Guided, cooperative learning, and individual knowledge acquisition. In L. B. Resnick (Ed.), Knowing, learning, and instruction: Essays in honor of Robert Glaser (pp. 393-451). Hillsdale, NJ: Lawrence Erlbaum Associates.

Brown, H. D. (2001). Teaching By Principles: An Interactive Approach to Language Pedagogy. Addison Wesley Longman, White Plains: NY.

Clement, R., Dörnyei, Z. \& Noels, K. (1994). Motivation, self-confidence and group cohesion in the foreign language classroom. Language Learning, 44, 417-448. https://doi.org/10.1111/j.1467-1770.1994.tb01113.x

Cohen, E. (1994). Designing Groupwork (2nd ed.). New York: Teacher College Press.

Damon, W. (1984). Peer education: The untapped potential. Journal of Applied Developmental Psychology, 5, 331-343. https://doi.org/10.1016/0193-3973(84)90006-6

Dörnyei, Z., \& Murphey, T. (2003). Group Dynamics in the Language Classroom. Cambridge University Press, Cambridge. https://doi.org/10.1017/cbo9780511667138

Ellis, R. (1994). The study of second language acquisition. Oxford: Oxford University Press.

Foster, P. (1998). A Classroom Perspective on the Negotiation of Meaning. Applied Linguistics, 19(1), 1-23. https://doi.org/10.1093/applin/19.1.1

Garrett, P., \& Shortall, T. (2002). Learners' evaluations of teacher fronted and student-centre classroom activities. Language Teaching Research, 6(1), 25-57. https://doi.org/10.1191/13621688021r096oa

Gass. S. M. (1997). Input, Interaction, and the Second Language Learner. Mahwah, NJ: Lawrence Erlbaum Associates.

Ghaith, G., \& Yaghi, H. (1998). Effect of Cooperative Learning on the Acquisition of Second Language Rules and Mechanics. Beirut: American University of Beirut.

Hall, D. R., \& Hewings, A. (2001). Innovation in English Language Teaching. London: Macquarie University and the Open University. https://doi.org/10.1093/elt/55.4.408

Harmer, J. (1991). The Practice of English Language Teaching. London: Longman.

Imai, Y. (2010). Emotions in SLA: New insights from collaborative learning for an EFL classroom. The Modern Language Journal, 94(2), 278-292. https://doi.org/10.1111/j.1540-4781.2010.01021.x

Krashen, S. (1982). Principle and Practice in Second Language Acquisition. Oxford: Pergamon.

Lier, L. (1996). Interaction in the language curriculum: awareness, autonomy and authenticity (Applied Linguistics and Language Study Series). London: Longman.

Lightbown, P. M., \& Spada, N. (1999). How Languages are Learned. Oxford: Oxford University Press.

Long, M. (1983). Native speaker/non-native speaker conversation and the negotiation of comprehensible input, Applied Linguistics, 4, 126-41. https://doi.org/10.1093/applin/4.2.126

Long, M. (1996). The role of the linguistic environment in second language acquisition. In W. Ritchie, \& T. Bhatia (Eds.), Handbook of Language Acquisition. Second Language Acquisition (pp. 413-468). New York: 
Academic Press. https://doi.org/10.1016/b978-012589042-7/50015-3

Martinez, R., Cheng, S., Smith, K., Smith, M., \& Yoon, Y. (2002). Indiana University Instructional Systems Technology (IST) Graduate Student Attitudes Towards Group Work. Indiana University. Strategies for educational inquiry Section 5982, Fall 2002 Group Project Reports. https://doi.org/10.1007/978-1-4757-4495-8

McCafferty, S. G., Jacobs, G. M., \& DaSilva Iddings, A. C. (2006). Cooperative Learning and Second Language Teaching. Cambridge: Cambridge University Press.

McDonough, K. (2004). Learner-Learner Interaction during Pair and Small group activities in Thai EFL context. Urbana: University of Illinois at Urbana-Champaign.

Oliver, R. (1998). Negotiation of meaning in child interactions. The Modern Language Journal, 3, 372-382. https://doi.org/10.1111/j.1540-4781.1998.tb01215.x

Oxford, R., \& Shearin, J. (1994). Language Learning Motivation: Expanding the Theoretical Framework. The Modern Language Journal, 78(1) 12-28. https://doi.org/10.1111/j.1540-4781.1994.tb02011.x

Pan, C. Y., \& Wu, H. Y. (2013). The cooperative learning effects on English reading comprehension and learning motivation of EFL freshmen. English Language Teaching, 6(5), 13. https://doi.org/10.5539/elt.v6n5p13

Pica, T. (1994). Review article: Research on negotiation: What does it reveal about second-language learning conditions, processes, and outcomes? Language Learning, 44, 493-527. https://doi.org/10.1111/j.1467-1770.1994.tb01115.x

Pica, T. (1996). Second language learning through interaction: multiple perspectives. Working Papers in Educational Linguistics, 12, 1-22.

Prichard, J. S. (2006). The educational impact of team-skills training: Preparing students to work in groups. British Journal of Educational Psychology, 76(1) 119-140. https://doi.org/10.1348/000709904X24564

Richards, J. C. (2005). Communicative language teaching today. SEAMEO Regional Language Centre.

Richard, J. C., \& Rodgers, T. S. (2001). Approaches and Methods in Language Teaching. Cambridge University Press. https://doi.org/10.1017/CBO9780511667305

Senior, R. (1997). Transforming language classes into bonded groups. ELT Journal, 51(1), 3-11. https://doi.org/10.1093/elt/51.1.3

Schinke-Llano, L., \& Vicars, R. (1993). The affective filter and negotiated interaction: Do our language activities

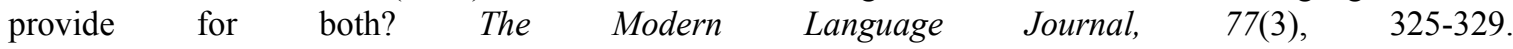
https://doi.org/10.1111/j.1540-4781.1993.tb01979.x

Sheikh, Sh. (1993). An assessment of communicative language teaching and its possible application to teaching English as a foreign language in the Saudi context, with particular reference to girls' secondary schools (Unpublished doctoral thesis), University of Bradford, Bradford, United Kingdom.

Slavin, R. E. (1983). Cooperative learning. New York: Longman.

Storch, N., \& Aldosari, A. (2010). Learners' use of first language (Arabic) in pair work in an EFL class. Language Teaching Research, 14(4), 355-375. https://doi.org/10.1177/1362168810375362

Swain, M. (1995). Three functions of output in second language learning. In G. Cook, \& B. Seidlhofer (Eds.), Principle and Practice in Applied Linguistics: Studies in Honour of H. G. Widdowson (pp. 125-144). Oxford: Oxford University Press.

Webba, N., \& Mastergeorgeb, A. (2003). Promoting effective helping behavior in peer-directed groups. International Journal of Educational Research, 39, 73-97. https://doi.org/10.1016/S0883-0355(03)00074-0

Zaid, M. (1993). Comprehensive analysis of the current system of teaching English as a foreign language in the Saudi Arabian intermediate schools (Unpublished doctoral dissertation) Boulder, University of Colorado, Colorado, United States.

\section{Copyrights}

Copyright for this article is retained by the author(s), with first publication rights granted to the journal.

This is an open-access article distributed under the terms and conditions of the Creative Commons Attribution license (http://creativecommons.org/licenses/by/4.0/). 